\title{
Using Sketches to Communicate Interaction Protocols of an Indigenous Community
}

\author{
Tariq Zaman \\ Faculty of Computer \\ Science and Information \\ Technology, Universiti \\ Malaysia Sarawak \\ zamantariq@gmail.c \\ om
}

\author{
Heike Winschiers- \\ Theophilus \\ Namibia University of \\ Science and \\ Technology \\ Windhoek, Namibia \\ hwinschiers@nust. \\ na
}

\author{
Franklin George, \\ Alvin Yeo Wee, \\ Hasnain Falak \\ ISITI, Universiti Malaysia \\ Sarawak \\ $\{f g 36093$, \\ awyeo289, \\ hasnainflk\}@gmail.c \\ om
}

\begin{abstract}
Being engaged in long term collaborations with indigenous communities requires a continuous adjustment of interaction protocols beyond set projects. Although the Long Lamai community in Malaysia developed a detailed cultural protocol for guest researchers, numerous conflicts were still recorded. In this paper we present our most recent approach to overcome the cross-cultural communication gaps using sketches, as developed by the local community members. We present a validation session that took place between the community members and guest researchers. We confirm the success of the sketch session, as guest researchers followed the underlying themes of the interaction protocols and internalised the concepts.
\end{abstract}

\section{CCS Concepts}

- Social and professional topics $\rightarrow$ Cultural characteristics

\section{Keywords}

Community engagement; Interaction protocols; Sketches;

\section{INTRODUCTION}

In community development discourse, "participation" of the community has always been promoted [6]; yet in practice community members are often reduced to informants only. This has strained relationships between community members and researchers. Often indigenous communities encounter new researchers with skepticism. Hence the researchers need to gain trust and develop a holistic understanding of the "context" in which the products and services are to be designed [20]. Indigenous and rural communities often possess limited technical expertise and lack the material means to successfully develop and implement the projects [14]. Merely guaranteeing the rights of the community to participate may not be sufficient, as the means for them to get involved are also necessary. However, the power to control the resources is often held by the governments and external stakeholders in projects involving communities, who do not value local communities as equal partners [11]. Real participation is only guaranteed if the problem, process, and anticipated solution are framed locally

Permission to make digital or hard copies of all or part of this work for personal or classroom use is granted without fee provided that copies are not made or distributed for profit or commercial advantage and that copies bear this notice and the full citation on the first page. Copyrights for components of this work owned by others than ACM must be honored. Abstracting with credit is permitted. To copy otherwise, or republish, to post on servers or to redistribute to lists, requires prior specific permission and/or a fee. Request permissions from Permissions@acm.org.

PDC '16, August 15-19, 2016, Aarhus, Denmark

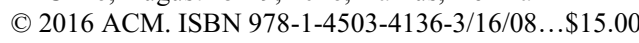

DOI: $\underline{\text { http://dx.doi.org/10.1145/2948076.2948088 }}$
[5]; this approach is especially necessary for indigenous and rural communities.

The interaction between researchers and local communities can be considered a multifaceted and continuous process of negotiations and participation [21]. Indigenous communities have diverse procedures, rules, and regulations that determine their interactions within the community, with outsiders, as well as with the territory and environment upon which they depend. Nonetheless, these norms are mainly in unwritten (tacit and implicit) forms and thus researchers are often unaware or do not understand these norms completely. This sometimes results in a failure to show respect, even though researchers demonstrate compassion. The failure to respect these norms, whether intentional or not, results in conflict and deterioration of relationships that could lead to failure of the collaboration [1].

The authors of this paper have been engaged in a long term partnership and joint endeavor of developing/using technologies for socio-economic development of the Penan community of Long Lamai, Malaysian Borneo. The community is receptive to new technologies and new joint project initiatives, including guest researchers from all over the world. Guest researchers are defined as those who have recently joined the project, and are new to the community. However the process of researchercommunity engagement has been challenging due to the social, cultural, and language differences. With the influx of projects and guest researchers a number of unresolved conflicts surfaced [22]. In response, the authors and community elders engaged in the process of co-developing new interaction protocols and coaching approaches for guest researchers and community members. Initially, published material was used to educate the guest researchers about the community's cultural protocols [23]; however, researchers often did not seem to have internalized it.

In this paper, we present our most recent approach: using sketches as a tool to create cross-cultural communication and interaction protocols for the Long Lamai community. Exploring alternative means of communication, young community member translated the existing cultural protocols into humorous though expressive sketches. These served as discussion probes between community members and guest researchers to better understand the underlying themes and issues depicted in the sketches.

\section{RELATED WORK}

\subsection{Community engagement}

The Digital Collectives in Indigenous Cultures and Communities meeting held in Hawaii brought together a number of representatives recommending respect of community's cultural values and their right to decide the degree 